\title{
Insertion of GPI-anchored alkaline phosphatase into supported membranes: a combined AFM and fluorescence microscopy study
}

\author{
Jean-Paul Rieu ${ }^{1 凶}$, Frédéric Ronzon ${ }^{2}$, Christophe Place ${ }^{3}$, Fairouz Dekkiche ${ }^{4}$, \\ Benjamin Cross $^{1}$ and Bernard Roux ${ }^{2}$
}
${ }^{1}$ Laboratoire de Physique de la Matière Condensée et Nanostructures, and ${ }^{2}$ Laboratoire de Physico-Chimie Biologique, Université Claude Bernard Lyon-1, 69622 Villeurbanne, France; ${ }^{3}$ Laboratoire de Physique, ENS Lyon, 69364 Lyon cedex 07, France; ${ }^{4}$ Laboratoire Pollution et Traitement des Eaux, Université Mentouri-Constantine, 25000 Constantine, Algeria

Received: 19 December, 2003; revised: 07 January, 2004; accepted: 06 February, 2004

Key words: GPI anchors, alkaline phosphatase, supported lipid membranes, fluorescent beads, atomic force microscopy (AFM)

\begin{abstract}
A new method based on combined atomic force microscopy (AFM) and fluorescence microscopy observations, is proposed to visualize the insertion of glycosylphosphatidyl inositol (GPI) anchored alkaline phosphatase from buffer solutions into supported phospholipid bilayers. The technique involves the use of $27 \mathrm{~nm}$ diameter fluorescent latex beads covalently coupled to the amine groups of proteins. Fluorescence microscopy allows the estimation of the relative protein coverage into the membrane and also introduces a height amplification for the detection of protein/bead complexes with the AFM. The coupling of the beads with the amine groups is not specific; this new and simple approach opens up new ways to investigate proteins into supported membrane systems.
\end{abstract}

Supported lipid-protein bilayers that restore the native environment of membrane proteins as well as their biological activity are widely used both for technical applications and for fundamental biomembrane studies
(Sackmann, 1996). Atomic force microscopy (AFM) is one of the preferred methods for studying these membrane structures as reviewed recently (Dufrêne \& Lee, 2000; Rinia $\&$ de Kruijff, 2001). The reviews include ho-

\footnotetext{
This work was supported by the National Center for Scientific Research (CNRS, France, ACI "Physico-chimie de la Matière Complexe" subsidy 2000).

${ }^{\bowtie}$ Corresponding author: fax: (33) 4724 32925; e-mail: rieu@lpmcn.univ-lyon1.fr

Abbreviations: AFM, atomic force microscopy; AP, alkaline phosphatase; APs, soluble alkaline phosphatase; GPI, glycosylphosphatidyl inositol; DPPC, dipalmitoylphosphatidylcholine; TBS, Tris-buffered saline.
} 
mogeneous lipid films, phase-separated films containing mixtures of lipids and other biomolecules such as peptides, membrane-bound biomolecules or integral proteins. For structural studies, membrane proteins such as ion channels or enzymes are reconstituted into supported bilayers at high concentrations. They form eventually crystallized 2D protein arrays which are investigated with AFM or cryo-electron microscopy (Werten et al., 2002). AFM also represents an useful tool to explore the organization of particular lipids and of non-crystallized membrane proteins in supported lipid bilayers (Mou et al., 1996; Yuan \& Johnston, 2001; Slade et al., 2002; Saslowsky et al., 2002; Milhiet et al., 2002a; 2002b).

A major problem in the application of AFM on biological samples is the relatively high force imposed. This is especially a problem for the upside leaflet of supported lipid layers which are non-crystallized nor firmly adsorbed on a solid substrate. The imaging force should be minimized less than $0.3 \mathrm{nN}$ (Milhiet et al., 2002a; 2002b) and even $0.1 \mathrm{nN}$ (Czajkowsky et al., 1999) in order to limit both vertical and lateral movements of proteins in the membrane that distort greatly the images. Such a low force is sometimes difficult to achieve for non highly specialized AFM. The analysis of biological samples with AFM is also often limited by the small field of view and slow scan rate. The need therefore arises for simple and versatile techniques that can be used to directly image membrane proteins in lipid membranes.

To overcome the difficulty, streptavidin-gold particles (Puu et al., 2000) or avidin (Kaasgaard et al., 2002) were bound to biotin molecules in the membrane. The height signal detected by the AFM is then amplified. Antibody labelling, when it is available, allows also the amplification of the topographic information for easy immunoassay and the specific detection of targeted proteins (Perrin et al., 1999). AFM may be also combined with an inverted or a confocal scanning laser mi- croscope when using fluorescence labelling techniques. The optical microscope allows rapid identification of areas of interest on the sample and accurate positioning of the tip thus opening many possibilities for observing cells (Putman et al., 1993) and supramolecular structures (Schabert et al., 1994).

In this paper, we report a new method to detect membrane proteins inserted into supported lipid membranes based on atomic force microscopy and fluorescence microscopy. We used carboxylate modified fluorescent microbeads that can be activated to bind covalently to the amine groups of proteins (Fig. 1). We have applied this method to characterize the spontaneous insertion into supported lipid bilayers of the intestinal alkaline phosphatase which has been recently investigated by AFM by several groups (Milhiet et al., 2002a; 2002b; Saslowsky et al., 2002). Mammalian alkaline phosphatases (AP) are glycosylphosphatidylinositol (GPI) anchored proteins that are localized on the outer layer of the plasma membrane (Nosjean et al., 1997; Lehto \& Sharom, 2002). The detailed molecular structure of GPI motif has been determined for several proteins (Fergusson, 1999). It is covalently attached to the C-termini of proteins and consists of a glycan chain bonded to phosphatidylinositol with two acyl chains anchored into the membrane bilayer. The active form of AP is a homodimer of $130 \mathrm{kDa}$. Each monomer contains 486 amino acids and one GPI-anchor. The X-ray resolved structure of AP from human placenta has recently been published (Le Du et $a l ., 2001)$. It presents about $90 \%$ sequence similarity with intestinal AP we have used in this study.

\section{MATERIALS AND METHODS}

\section{Formation of supported lipid bilayers.}

The solid-supported lipid bilayers were prepared using Langmuir-Blodgett depositions (Fig. 1A) at a transfer rate of $0.5 \mathrm{~mm} / \mathrm{min}$ 
and at a lateral pressure of $40 \mathrm{mN} / \mathrm{m}$. Dipalmitoylphosphatidylcholine (DPPC) was purchased from Avanti Polar Lipids. Monolayers were formed on a pure milliQ- $\mathrm{H} 2 \mathrm{O}$ (Millipore) subphase using a Langmuir trough (NIMA, England) by spreading a 0.5 $\mathrm{mM}$ phospholipid solution in chloroform/ethanol (9:1, v/v). Surfaces of borosilicate glass
$36 \mathrm{~h}$ with bilayers while maintaining a minimum agitation (Fig. 1B).

Bead coupling. The commercially available micrometric fluobeads (Yellow-green, $27 \mathrm{~nm}$ diameter, Molecular Probes) have pendant carboxylic acids on their surface. Activation of the carboxylic groups in water with $N$-hydroxysulfosuccinimide (sulfo-NHS), 1-ethyl-3-(3-di-
(A) Langmuir-Blodgett deposition

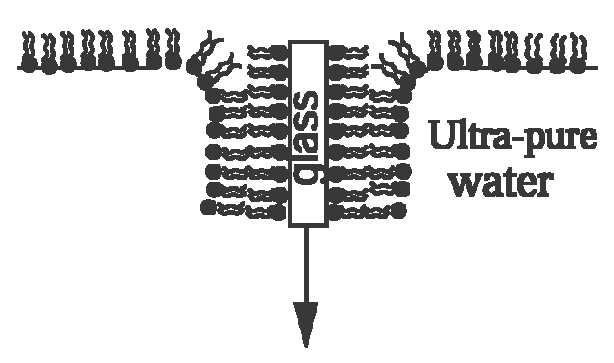

(B) Protein incubation

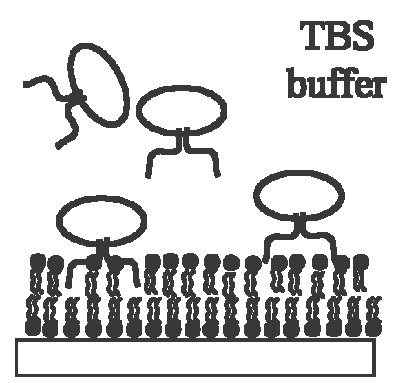

(C) Bead coupling

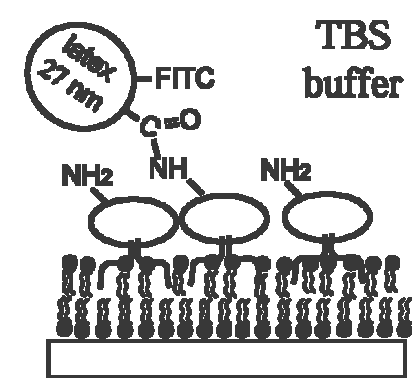

Figure 1. Schematic representation of the different steps of membrane reconstitution.

(A) Preparation of supported phospholipid bilayers using Langmuir-Blodgett deposition. (B) Incubation of GPI-proteins in TBS during $36 \mathrm{~h}$ under gentle agitation. (C) Coupling of activated fluobeads with proteins. Other explanations are given in the Materials and Methods.

$\left(15 \times 15 \times 2 \mathrm{~mm}^{3}\right)$ were used for depositions. They were sonicated twice $60 \mathrm{~min}$ at $50^{\circ} \mathrm{C}$ in aqueous detergent Micro90 (Fisher-Bioblock, France), and then rinsed copiously with ultra-pure water. Supported bilayers were conserved in small dishes containing about $3 \mathrm{ml}$ water. The subphase was changed to TBS buffer (Tris/ $\mathrm{HCl} 10 \mathrm{mM}, \mathrm{NaCl} 150 \mathrm{mM}, \mathrm{Mg}^{++}$ $1 \mathrm{mM}, \mathrm{pH}=8.5$ ) before and after protein or bead incubation.

Proteins. AP of bovine intestine was purified as described by Angrand et al. (1997) and modified by Ronzon et al. (2002). The enzyme was purified by immunoaffinity chromatography and then precipitated by acetone in order to remove all residual lipids. The suspension was centrifugated and the pellet was dried under nitrogen before being homogenized in TBS buffer with $2 \mathrm{mM}$ n-octyl $\beta$-D-glucopyranoside $(\beta \mathrm{OG})$. The protein concentration was measured by the method of Read and Northcote (1981) using bovine serum albumin as standard. Protein incubated during methylaminopropyl) carbodiimide-HCl (EDC) makes them suitable for covalent coupling with the amine groups of proteins (lysine and N-terminal). The commercial bead storage buffer is exchanged on micro chromatography column (P6, Bio-rad) to activation buffer, $\mathrm{pH}=$

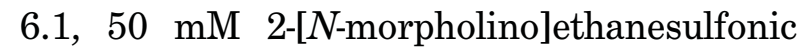
acid (Mes), $500 \mathrm{mM} \mathrm{NaCl}$. The beads (200 $\mu \mathrm{l}$, $3.25 \mu \mathrm{M})$ in activation buffer are exposed to EDC (20 $\mu \mathrm{l}, 200 \mathrm{mM})$ and sulfo-NHS (20 $\mu \mathrm{l}$, $500 \mathrm{mM}$ ) and stirred for $60 \mathrm{~min}$. The reaction is then stopped with pure $\beta$-mercaptoethanol ( $4 \mu \mathrm{l}, 14 \mathrm{M})$. The small reactants are removed on a gel exclusion micro-chromatography column and the activated beads stored at $4^{\circ} \mathrm{C}$ in storage buffer $(10 \mathrm{mM}$ Tris $/ \mathrm{HCl}, \mathrm{pH}=7.4$, $0.02 \%$ sodium azide). The coupling is then performed by exposure to activated microbeads $\left(2.6 \times 10^{11}\right.$ beads $)$ of the mixed bilayers overnight at room temperature in coupling buffer ( $3 \mathrm{ml}$, TBS, $\mathrm{pH}=8.5$ ), under gentle agitation (Fig. 1C). 
Microscopy and image processing. A stand-alone Topometrix Explorer AFM (CA, U.S.A.) equipped with liquid scanners was directly plunged into the dishes containing the supported bilayers. Images of mixed bilayers were obtained in liquid contact mode with the dedicated software (Leica IM50). We collected $0.75 \mathrm{~s}$ exposure images at $1300 \times 1030$ pixels. All the observations were taken at room temperature with the same camera settings. We measured the mean intensity $I_{b}$ with Scion-image free software (http://www.
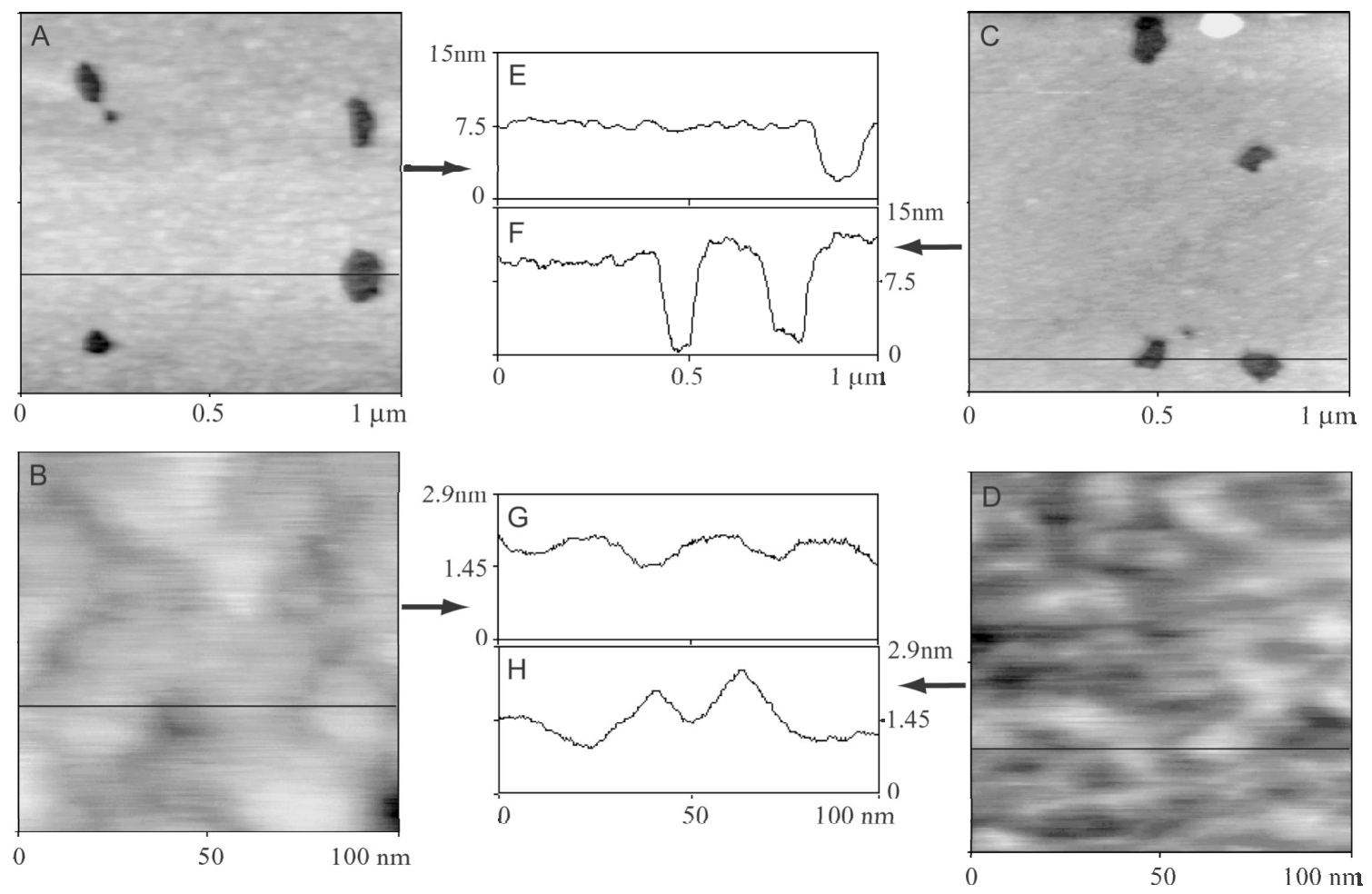

Figure 2. AFM images in TBS of supported membranes.

(A), (B) Pure DPPC bilayer at different scales, and (C), (D) the same bilayer after its incubation during $36 \mathrm{~h}$ in 3.2 $\mu \mathrm{g} / \mathrm{ml}$ of $\mathrm{AP}_{\mathrm{GPI}}$. The vertical color scales correspond to (A) $10.5 \mathrm{~nm}$, (B) $2.8 \mathrm{~nm}$, (C) $16.5 \mathrm{~nm}$ and (D) $2.9 \mathrm{~nm}$. (E)-(H) Section lines of images (A)-(D).

$200 \mu \mathrm{m}$ silicon nitride cantilevers (Topometrix, 1520-00) with nominal spring constant of $0.03 \mathrm{~N} / \mathrm{m}$ operating at forces less than $0.3 \mathrm{nN}$. Images of mixed bilayers with fluobeads were obtained in liquid tapping mode with $100 \mu \mathrm{m}$ silicon nitride cantilevers (Topometrix, 1530-00) with nominal spring constant of $0.3 \mathrm{~N} / \mathrm{m}$ operating with a driving frequency of about $60 \mathrm{kHz}$. For fluorescence microscopy observations, we used a microscope (Leica, DM LM) equipped with a mercury lamp, a standard blue filter (I3, Leica), a $20 \times$ objective (Leica PL Fluotar) and cooled CCD camera (Leica DC 350F) running under scioncorp.com). $I_{b}$ is defined in (\%) as $I_{b}=\left(I_{\text {in }}-I_{\text {out }}\right) / 256$ where $I_{\text {in }}$ is the mean intensity in the illuminated area, $I_{\text {out }}$ the mean intensity outside and 256 is the value of saturated bright pixels.

\section{RESULTS}

Supported DPPC bilayers deposited in the gel phase at $40 \mathrm{mN} / \mathrm{m}$ were first imaged in TBS buffer before protein incubation. The AFM images show as black regions some minor holes in the lipid bilayer membranes 
(Fig. 2A). The depth of the holes is around $6.0 \pm 0.5 \mathrm{~nm}$ consistent with a DPPC bilayer deposited on the glass surface as previously measured by AFM (Mou et al., 1996). Over a $100 \times 100 \mathrm{~nm}^{2}$ region (Fig. 2B), the bilayer plateau displays a smooth granular structure with a maximum peak to valley height of 1.2 $\mathrm{nm}$, a mean grain diameter of about $25 \mathrm{~nm}$ and a root mean squared (rms) roughness of $0.3 \mathrm{~nm}$. This topography is in accordance with the borosilicate glass surface under the bilayer (Rieu et al., 2002).

The bilayer was then incubated during $36 \mathrm{~h}$, in the presence of $3.2 \mu \mathrm{g} / \mathrm{ml}$ of $\mathrm{AP}_{\mathrm{GPI}}$. It still presents holes with the approximate same diameter but with a larger depth (i.e., $9 \pm 0.5$ $\mathrm{nm}$ in Fig. 2C). As the general shape of the protein may be assimilated to a $10 \times 5 \mathrm{~nm}$ prolate ellipsoid of revolution (Le $\mathrm{Du}$ et al., 2001), the depth of the holes in Fig. $2 \mathrm{C}$ is in accordance with a pure DPPC bilayer with a al., 2002) while the incubation of AP with supported mixed bilayers, resulted in the apparition of dots protruding by 2 to $5 \mathrm{~nm}$ from the membrane (Milhiet et al., 2002a; 2002b). At smaller scales, this bilayer shows a granular structure with a shorter characteristic grain diameter than before incubation, i.e., 10-15 $\mathrm{nm}$, a larger peak to valley height, i.e., $2 \mathrm{~nm}$, and a larger $\mathrm{rms}$ roughness, i.e., $0.4 \mathrm{~nm}$ (Fig. 2D). This suggests that each protrusion corresponds to a single protein. The proteins are homogeneously distributed in the membrane with a surface coverage of about $10 \%$ obtained by counting the number of individual protrusions. When supported bilayers were incubated with a significantly smaller protein concentration (i.e., $0.16 \mu \mathrm{g} / \mathrm{ml}$ or smaller), we never observed by AFM any clear differences from the pure phospholipid bilayers except for the presence of a few dots (image not shown). These dots with a diameter ranging
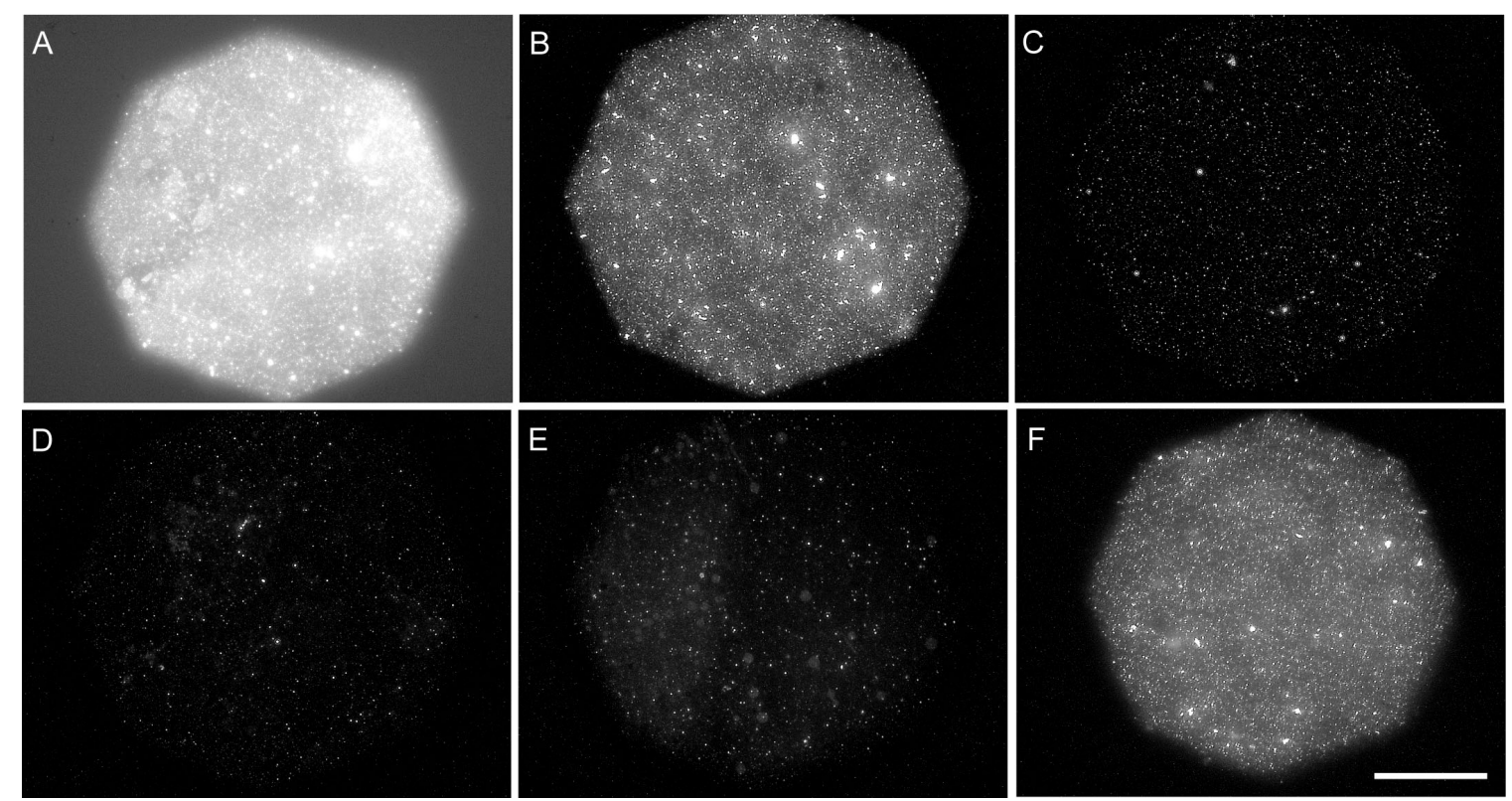

Figure 3. Fluorescent images of fluobeads coupled on different surfaces.

(A)-(C) Supported DPPC bilayers which incubated in presence of (A) $3.2 \mu \mathrm{g} / \mathrm{ml} \mathrm{AP} \mathrm{GPI}_{\mathrm{G}}$, (B) $1.6 \mu \mathrm{g} / \mathrm{ml} \mathrm{AP} \mathrm{GPI}$, (C) $0.16 \mu \mathrm{g} / \mathrm{ml} \mathrm{AP} \mathrm{GPI}_{\text {; }}$ (D) bare DPPC bilayer; (E) DPPC bilayer which incubated in presence of $1.66 \mu \mathrm{g} / \mathrm{ml} \mathrm{APS}$; (F) bare hydrophilic glass. All images were taken with the same amount of beads $\left(2.6 \times 10^{11}\right.$ beads in $3 \mathrm{ml}$ TBS$)$, the same exposure time and the same camera settings. Bar, $100 \mu \mathrm{m}$.

protein layer above. When they are adsorbed directly on bare substrates, single or aggregated proteins protrude by 3 to $5 \mathrm{~nm}$ (Rieu et from 30 to $80 \mathrm{~nm}$ and a height from 2 to $8 \mathrm{~nm}$, were presumably individual proteins or small protein aggregates. 
In order to explore the sample homogeneity, we observed by fluorescence microscopy fluobeads covalently coupled to the amine groups of the proteins reconstituted in DPPC bilayers. Fluorescence images are shown in Fig. 3. The intensity clearly depends on the amount of $\mathrm{AP}_{\mathrm{GPI}}$ used during incubation (Figs. 2A-D). Bilayers in contact with a high protein concentration (Figs. 3A, B) show a high overall baseline fluorescence as well as a large number and large size of bright aggregates. These aggregates correspond probably to regions of the bilayer with a dense protein coverage such as the one of Figs. 1C-D. At smaller concentrations (Fig. 3C) or without proteins (Fig. 3D), there are only small weakly fluorescent dots corresponding probably to single beads or small aggregates. The mean intensities for the concentrations used in Figs. 2A-D are respectively $I_{b}=52 \pm 13 \%$, $25 \pm 8 \%, 16.5 \pm 3 \%$ and $13.5 \pm 3 \%$ (mean \pm standard deviation of different images taken for each concentration). For amounts lower than $0.16 \mu \mathrm{g} / \mathrm{ml} \mathrm{AP}$ GPI (not shown), the intensity is no longer distinguishable from the non-specific adsorption of beads on pure DPPC bilayers (Fig. 3D). Non specific adsorption on bare hydrophilic glass (Fig. 3F, $I b=37 \pm 6 \%$ ) is more important than on pure DPPC bilayers (Fig. 3D). When the DPPC bilayer incubated in $1.66 \mu \mathrm{g} / \mathrm{ml}$ soluble of $\mathrm{AP}_{\mathrm{S}}$ (protein lacking GPI anchors, Fig. 3E), the fluorescence intensity $\left(I_{b}=17.5 \pm 5.5 \%\right)$ is lower than when using almost the same amount of $\mathrm{AP}_{\mathrm{GPI}}$ (Fig. 3B, $25 \pm 8 \%$ ). The observed fluorescence of $\mathrm{AP}_{\mathrm{S}}$ is only slightly larger from the case of non specific adsorption of beads on pure phospholipids bilayers (Fig. 3D, $13.5 \pm 3 \%$ ). As expected, it indicates that the GPI anchors favour greatly the insertion of AP in bilayers and that APS only weakly interacts with the DPPC bilayer.

The number of beads was chosen throughout this study in order its developed area corresponds roughly to the glass area. We checked that at constant protein concentration, fluorescence intensity increases with bead concentration. However, when using a too large bead concentration, although intensity is still increasing with protein concentration, it is no more possible to record simultaneously the intensity from single beads and aggregates due to the finite dynamic range of the camera and the optical resolution (i.e., about $0.8 \mu \mathrm{m}$ ) much larger than the bead size.

Beads covalently coupled to GPI-anchored proteins can be easily detected by AFM at scales $5-100 \mu \mathrm{m}$. Figure 4 shows particles protruding $20-30 \mathrm{~nm}$ from a bilayer which was incubated with $3.2 \mu \mathrm{g} / \mathrm{ml}$ of protein. This
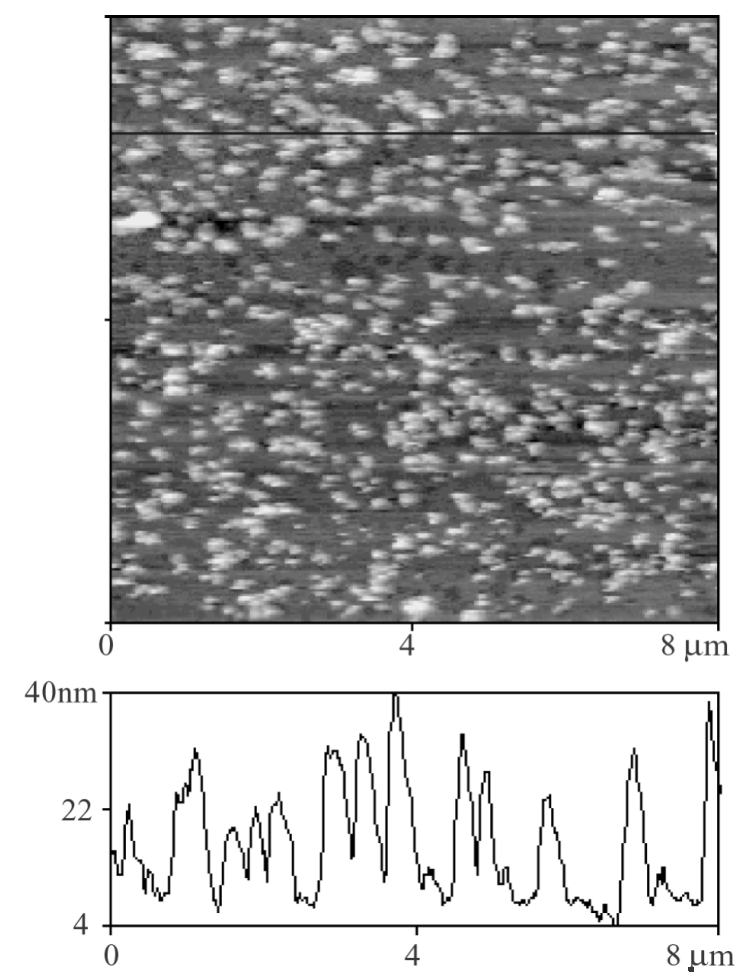

Figure 4. AFM image of a supported bilayer whith proteins and beads.

The DPPC bilayer incubated in presence of $3.2 \mu \mathrm{g} / \mathrm{ml}$ of $\mathrm{AP}_{\mathrm{GPI}}$ and fluobeads. The image was taken in TBS using tapping mode AFM. The vertical color scale corresponds to $50 \mathrm{~nm}$.

height corresponds to the bead size reported from the manufacturer (i.e., $27 \mathrm{~nm}$ ). In the middle, holes that become much clear when zooming are present. Beads appear elongated in the scan direction because they are easily shifted when scanning. For this reason, we 
obtained the best images of beads in tapping mode AFM.

\section{DISCUSSION}

The aim of this work was to determine the spatial organization of inserted GPI-anchored alkaline phosphatase within supported phospholipids bilayers. Several recent studies demonstrated that GPI proteins may be spontaneously incorporated into supported lipid bilayers and individually detected by AFM (Milhiet et al., 2002a; 2002b, Saslowsky et al., 2002). In these studies, bilayers were incubated in the presence of $30-50 \mu \mathrm{g} / \mathrm{ml}$ of protein. We also detected in DPPC bilayers a large protein coverage when using a 10 fold smaller protein concentration, i.e., $3.2 \mu \mathrm{g} / \mathrm{ml}$ (Figs. 1C-D). However, at lower protein concentrations, it is not easy to detect proteins sparsely distributed in the membrane due to (i) the low force necessary to image anchored proteins, (ii) the small field of view of the AFM and (iii) the very heterogeneous protein distribution revealed by the fluorescent beads at scales smaller than $50 \mu \mathrm{m}$ (Fig. 3). Coupling the proteins with fluorescent beads allows their easiest detection both in fluorescence and AFM. It is worth noting that the approach can be used with all proteins as it does not require the availability of labelled antibodies.

The main limitations of the method are the non specific bead adsorption for small protein concentrations ( $\leq 0.16 \mu \mathrm{g} / \mathrm{ml}$ in our case), and the optical resolution for high protein concentrations ( $\mathrm{C} \geq 3.2 \mu \mathrm{g} / \mathrm{ml}$ with the bead concentration used for this study). By imaging protein-bead complexes with the AFM, the latter limitation vanishes. We never obtained bead coverage significantly higher than that of Fig. 4 while the number of beads is theoretically sufficient for a full surface coverage. On the other hand, the protein coverage directly observed by AFM at similar protein concentration is much larger (Fig. 2).
The first explanation for this discrepancy is that all beads do not bind to proteins. They stay in solution or bind to the plastic dish because they do not find amine groups during the incubation time (12-15 h). The discrepancy may be also due to a clustering of proteins by beads. The large bead surface might indeed cross-link two or more proteins at long times even if the protein diffusion in the gel phase of DPPC bilayers is low. The fact that clusters of beads are visible both in fluorescence and AFM images (Figs. 2 and 3) supports this hypothesis.

Given the above mentioned limitations, the method provides a relative estimate of the protein coverage. We found that the mean intensity depends on the protein type $\mathrm{AP}_{\mathrm{GPI}}$ or $\mathrm{AP}_{\mathrm{S}}$, Figs. 2B, E). As expected, the GPI anchors favour greatly the insertion of AP in bilayers. Intensity depends also on the $\mathrm{AP}_{\mathrm{GPI}}$ concentration during incubation (Figs. $2 \mathrm{~A}-\mathrm{D}$ ). This is again expected but was not found from previous AFM studies which used larger protein concentration (Milhiet et al., 2002a; 2002b; Saslowsky et al., 2002). It is interesting to note that incubation in $1.6 \mu \mathrm{g} / \mathrm{ml}$ $\mathrm{AP}_{\mathrm{GPI}}$ (Fig. 3B) does not saturate the membrane as fluorescence is much higher in presence of $3.2 \mu \mathrm{g} / \mathrm{ml} \mathrm{AP}$ GPI (Fig. 3A). However, $1.6 \mu \mathrm{g} / \mathrm{ml}$ of proteins in $3 \mathrm{ml}$ corresponds to a theoretical developed area of $11 \mathrm{~cm}^{2}$ that is larger than the bilayer area $\left(2.25 \mathrm{~cm}^{2}\right.$ of the glass area). Thus the effectiveness of GPI insertion in preformed bilayers is very low in agreement with previous works that report that most efficient reconstitution of $\mathrm{AP}_{\mathrm{GPI}}$ into liposome was obtained when the liposomes were partially solubilized (Angrand et al., 1997; Nosjean \& Roux, 1999; Morandat et al., 2002).

Further work is required to achieve a more quantitative measurement of the protein coverage and to suppress the steric hindrance that can prevent the protein/marker interaction. The use of new fluorescent derivatives (Lehto \& Sharom, 2002) for AP labeling is in progress in our laboratory. We would like 
then to understand the origin of the heterogeneous protein distribution as observed in biological membranes using lipid mixtures.

\section{R E F E R E N C E S}

Angrand M, Briolay A, Ronzon F, Roux B. (1997) Detergent-mediated reconstitution of a glycosylphosphatidylinositol-protein into liposomes. Eur J Biochem.; 250: 168-76.

Czajkowsky DM, Iwamoto H, Cover TL, Shao Z. (1999) The vacuolating toxin from

Helicobacter pylori forms hexameric pores in lipid bilayers at low pH. Proc Nat Acad Sci $U S$ A.; 96: 2001-6.

Dufrêne YF, Lee GU. (2000) Direct characterization of the physicochemical properties of fungal spores using functionalized AFM probes. Biochim Biophys Acta.; 1509: 14-41.

Ferguson MA. (1999) The structure, biosynthesis and functions of glycosylphosphatidylinositol anchors, and the contributions of trypanosome research. $J$ Cell Sci.; 112: 2799-809.

Kaasgaard T, Mouritsen OG, Jorgensen K. (2002) Lipid domain formation and ligand-receptor distribution in lipid bilayer membranes investigated by atomic force microscopy. FEBS Lett.; 515: 29-34.

Le Du MH, Stigbrand T, Taussig MJ, Ménez A, Stura EA. (2001) Crystal structure of alkaline phosphatase from human placenta at $1.8 \AA$ resolution. Implication for a substrate specificity. J Biol Chem.; 276: 9158-65.

Lehto MT, Sharom FJ. (2002) Proximity of the protein moiety of a GPI-anchored protein to the membrane surface: a FRET study. Biochemistry.; 41: 8368-76.

Milhiet PE, Giocondi MC, Baghdadi O, Ronzon F, Roux B, LeGrimellec C. (2002a) Spontaneous insertion and partitioning of alkaline phosphatase into model lipid rafts. $E M B O$ Rep.; 5: 485-90.

Milhiet PE, Giocondi MC, Baghdadi O, Ronzon F, LeGrimellec C, Roux B. (2002b) AFM characterization of model rafts in supported bilayers. Single Mol.; 3: 136-41.

Morandat S, Bortolato M, Roux B (2002) Cholesterol-dependent insertion of glycosylphosphatidylinositol-anchored enzyme. Biochim Biophys Acta.; 1564: 473-8.

Mou J, Czajkowsky DM, Shao Z. (1996) Gramicidin A aggregation in supported gel state phosphatidylcholine bilayers. Biochemistry.; 35: 3222-26.

Nosjean O, Briolay A, Roux B. (1997) Mammalian GPI proteins: sorting, membrane residence and functions. Biochim Biophys Acta; 1331: 153-86.

Nosjean O, Roux B. (1999) Ectoplasmic insertion of a glycosylphosphatidylinositol-anchored protein in glycosphingolipid- and cholesterol-containing phosphatidylcholine vesicles. Eur J Biochem.; 263: 865-70.

Perrin A, Theretz A, Lanet V, Vialle S, Mandrand B. (1999) Immunomagnetic concentration of antigens and detection based on a scanning force microscopic immunoassay. J Immunol Methods.; 224: 77-87.

Putman CAJ, van Leeuwen AM, de Grooth BG, Radosevic K, van der Werf K, van Hulst NF, Greve J. (1993) Atomic force microscopy combined with confocal laser scanning microscopy: A new look at cells. Bioimaging.; 1: 63-70.

Puu G, Artursson E, Gustafson I, Lundstrom M, Jass J. (2000) Distribution and stability of membrane proteins in lipid membranes on solid supports. Biosens Bioelectron.; 15: $31-41$.

Read SM, Northcote DH. (1981) Minimization of variation in the response to different proteins of the Coomassie blue G dye-binding assay for protein. Anal Biochem.; 116: 53-64.

Rieu J-P, Ronzon F, Roux B. (2002) Adsorption and aggregation of glycosylphosphatidyl inositol (GPI) anchored alkaline phosphatase on methylated glass surfaces studied by tapping mode atomic force microscopy. Thin Solid Films.; 406: 241-9. 
Rinia HA, de Kruijff B. (2001) Imaging domains in model membranes with atomic force microscopy. FEBS Lett.; 504: 194-9.

Ronzon F, Desbat B, Buffeteau T, Mingotaud C, Chauvet J-P, Roux B. (2002) Structure and orientation of a glycosylphosphatidyl inositol anchored protein at the air/water interface. J Phys Chem B.; 106: 3307-15.

Sackmann E. (1996) Supported membranes: scientific and practical applications. Science.; 271: $43-8$.

Saslowsky DE, Lawrence J, Ren X, Brown DA, Henderson RM, Edwardson JM. (2002) Placental alkaline phosphatase is efficiently targeted to rafts in supported lipid bilayers. $J$ Biol Chem.; 277: 26966-70.

Schabert F, Knapp H, Karrasch S, Häring R, Engel A. (1994) Confocal scanning laser scanning probe hybrid microscope for biological applications. Ultramicroscopy.; 53: 147-57.

Slade A, Luh J, Ho S, Yip CM. (2002) Single molecule imaging of supported planar lipid bilayer reconstituted human insulin receptors by in situ scanning probe microscopy. $J$ Struct Biol.; 137: 283-91.

Werten PJ, Rémigy H-W, de Groot BL, Fotiadis D, Philippsen A, Stahlberg H, Grubmüller H, Engel A. (2002) Progress in the analysis of membrane protein structure and function. FEBS Lett.; 529: 65-72.

Yuan C, Johnston LJ. (2001) Atomic force microscopy studies of ganglioside GM1 domains in phosphatidylcholine and phosphatidylcholine/cholesterol bilayers. Biophys J.; 81: 1059-69. 